\title{
Pendugaan Potensi Bijih Besi Di Desa Bulik Kecamatan Nanga Bulik Kabupaten Lamandau Kalimantan Tengah Dengan Metode Geomagnet
}

\author{
Joko Sampurno*) \\ *) Jurusan Fisika, FMIPA Universitas Tanjungpura \\ Email : jks_fisika@yahoo.com
}

\begin{abstract}
Abstrak
Telah dilakukan eksplorasi bijih besi (iron ore) di Desa Bulik Kecamatan Nanga Bulik Kabupaten Lamandau Kalimantan Tengah. Tujuan eksplorasi ini adalah untuk mengidentifikasi sebaran dan jenis jenis bijih besi. Eksplorasi dilakukan menggunakan metode geomagnet yang memanfaatkan nilai medan magnet bumi untuk mengidentifikasi nilai suseptibilitas mineral yang terdapat di kerak bumi. Hasil peneletian menunjukan adanya keberadaan bijih besi berjenis hematit di empat titik lokasi pengendapan.
\end{abstract}

Kata Kunci: Desa Bulik, bijih besi, geomagnet, suseptibilitas

\section{Pendahuluan}

Berdasarkan pengamatan di lapangan, diperoleh informasi bahwa kawasan pedataran yang terletak di Desa Bulik Kecamatan Nanga Bulik Kabupaten Lamandau Kalimantan Tengah memiliki potensi bijih besi berupa batuan besi berwarna hitam kemerahan yang diduga sebagai hematit. Oleh sebab itu, perlu dilakukan survei geofisika sehingga dapat diperkirakan jenis batuan, sebaran maupun cadangan bijih besi di kawasan tersebut.

Kebanyakan bijih besi seperti magnetit $\left(\mathrm{Fe}_{3} \mathrm{O}_{4}\right)$, ilmenit $\left(\mathrm{FeTiO}_{3}\right)$, pirit $(\mathrm{FeS})$, dan hematit $\left(\mathrm{FeO}_{2}\right)$ merupakan jenis mineral ferrimagnetik yang memiliki suseptibilitas tinggi. Mineral tersebut terinduksi oleh medan magnet bumi dan menimbulkan medan sekunder. Medan sekunder ini akan menimbulkan perbedaan kontras suseptibilitas pada tubuh cebakan dari daerah sekelilingnya. Karena alasan ini maka metode geofisika yang paling akurat untuk eksplorasi bijih besi adalah metode geomagnet. Metode ini telah banyak diaplikasikan oleh para peneliti diantaranya yang dilakukan oleh Sharma (1987), Savray,dkk (2006), dan Ramakrishna, T.S.(2012).

\section{Landasan Teori}

Batuan di dalam bumi mengandung mineral-mineral yang sebagian juga memiliki sifat kemagnetan. Mineral tersebut terinduksi medan magnet bumi dan menimbulkan medan magnet sekunder (Bakrie, 2008). Hal inilah yang menjadi dasar metode geomagnet.

Metode geomagnet didasarkan pada pengukuran variasi intensitas magnetik di permukaan bumi yang disebabkan adanya variasi distribusi (anomali) benda termagnetisasi di bawah permukaan bumi. Pola anomali ini dicirikan oleh pergantian antara anomali positif - negatif dan sejajar dengan sumbu pemekarannya (Gambar 1).

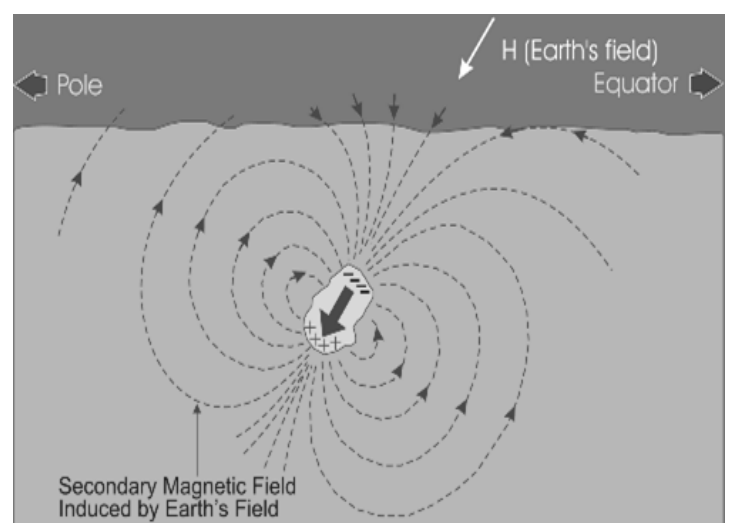

Gambar 1. Induksi magnet bumi pada mineral magnetik (Bakrie, 2008)

Intensitas $\begin{gathered}\text { medan } \\ \text { diukur }\end{gathered}$
$\begin{aligned} & \text { magnet di } \\ & \text { menggunakan } \\ & \text { pengukuran }\end{aligned}$
magnetometer.
magnetometer berupa penjumlahan dari medan
magnet bumi utama, variasi medan magnet
bumi yang berhubungan dengan variasi
kerentanan magnet batuan, medan magnet
remanen dan variasi harian akibat aktivitas
matahari. Penyebab timbulnya anomali medan
magnetik pada suatu wilayah dapat
diilustrasikan pada gambar berikut (Gambar 2).




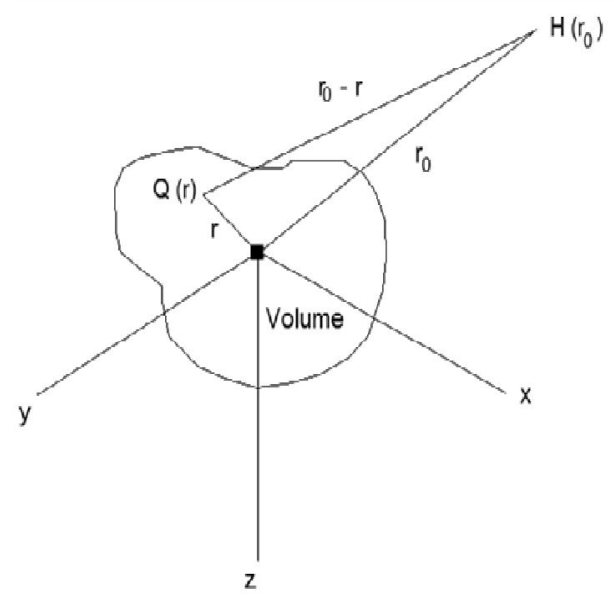

Gambar 2. Ilustrasi penyebab timbulnya medan magnetik anomali (Telford, dkk, 1979)

Berdasarkan Gambar 2, potensial skalar medan suatu material magnetik pada suatu titik diluar material tersebut dinyatakan sebagai (Telford, dkk, 1979):

$A=-\int_{V} \vec{M} \bullet \nabla\left[\frac{1}{\left|\vec{r}_{0}-\vec{r}\right|}\right] d V$

dengan

$\vec{M}=$ vektor magnetisasi material magnetik $(\mathrm{A} / \mathrm{m})$

$\vec{r}_{0}=$ vektor posisi dari sumber dipol material magnetik (m)

$V=$ volume suatu sumber dipol material magnetik $\left(\mathrm{m}^{3}\right)$

$A=$ potensial skalar medan material magnetik (A)

Intensitas suatu material magnetik dinyatakan dalam (Telford, $d k k, 1979$ ):

$\vec{H}=-\nabla A(\vec{r})$

Jika Persamaan (1) disubstitusikan ke dalam Persamaan (2) maka diperoleh

$\vec{H}\left(r_{0}\right)=\nabla \int_{V} \vec{M}(\vec{r}) \bullet \nabla\left[\frac{1}{\left|\vec{r}_{0}-\vec{r}\right|}\right] d V$

Jika $\vec{M}$ adalah vektor konstan dengan arah $\alpha$ $=l i+m j+n k$, maka

$$
\vec{M} \bullet \nabla=M \frac{\partial}{\partial \alpha}=M\left(l \frac{\partial}{\partial x}+m \frac{\partial}{\partial y}+n \frac{\partial}{\partial z}\right)
$$

$A=-M \frac{\partial}{\partial \alpha} \int_{V}\left(\frac{d V}{\left|\vec{r}_{0}-\vec{r}\right|}\right)$

Jika $\vec{H}_{e}$ merupakan medan magnet bumi dan $\vec{H}\left(r_{0}\right)$ merupakan medan material magnetik di suatu permukaan bumi maka medan magnetik totalnya dinyatakan dengan (Telford, dkk, 1979):

$$
\vec{H}=\vec{H}_{e}+\vec{H}\left(r_{0}\right)
$$

Arah $\vec{H}_{e}$ dan $\vec{H}\left(r_{0}\right)$ tidak mesti sama. Jika $\vec{H}\left(r_{0}\right)$ jauh lebih kecil dari $\vec{H}_{e}$ atau dengan kata lain tidak ada material yang menghasilkan magnetisasi residu maka $\vec{H}$ dan $\vec{H}_{e}$ memiliki arah yang sama. Apabila $\vec{H}\left(r_{0}\right)$ merupakan suatu fraksi nilai yang cukup besar (25\% atau lebih) dari $\vec{H}_{e}$ dan memiliki arah yang berbeda maka komponen $\vec{H}\left(r_{0}\right)$ dalam arah $\vec{H}_{e}$ menjadi (Telford, $d k k, 1979$ ) :

$$
H_{D}=-\vec{f}_{1} \bullet \nabla A=-\frac{\partial A}{\partial f}=M \frac{\partial^{2}}{\partial \alpha \partial f} \int_{V} \frac{d V}{\left|\vec{r}_{0}-\vec{r}\right|}
$$

yang mana $\vec{f}_{1}$ merupakan vektor unit dalam arah $\vec{H}_{e}$. Jika magnetisasi utama diinduksikan oleh $\vec{H}_{e}$ maka (Telford, dkk, 1979):

$$
H_{D}\left(r_{0}\right)=M \frac{\partial^{2}}{\partial f^{2}} \int_{V} \frac{d V}{\left|\vec{r}_{0}-\vec{r}\right|}=k H_{e} \frac{\partial^{2}}{\partial f^{2}} \int_{V} \frac{d V}{\left|\vec{r}_{0}-\vec{r}\right|}
$$

\section{Lokasi Penelitian}

Lokasi penelitian dilakukan di Desa Bulik, Kecamatan Nanga Bulik Kabupaten Lamandau, Kalimantan Tengah. Lokasi peninjauan berjarak $25 \mathrm{~km}$ di bagian Barat dari Ibukota Kabupaten Lamandau.

dan 


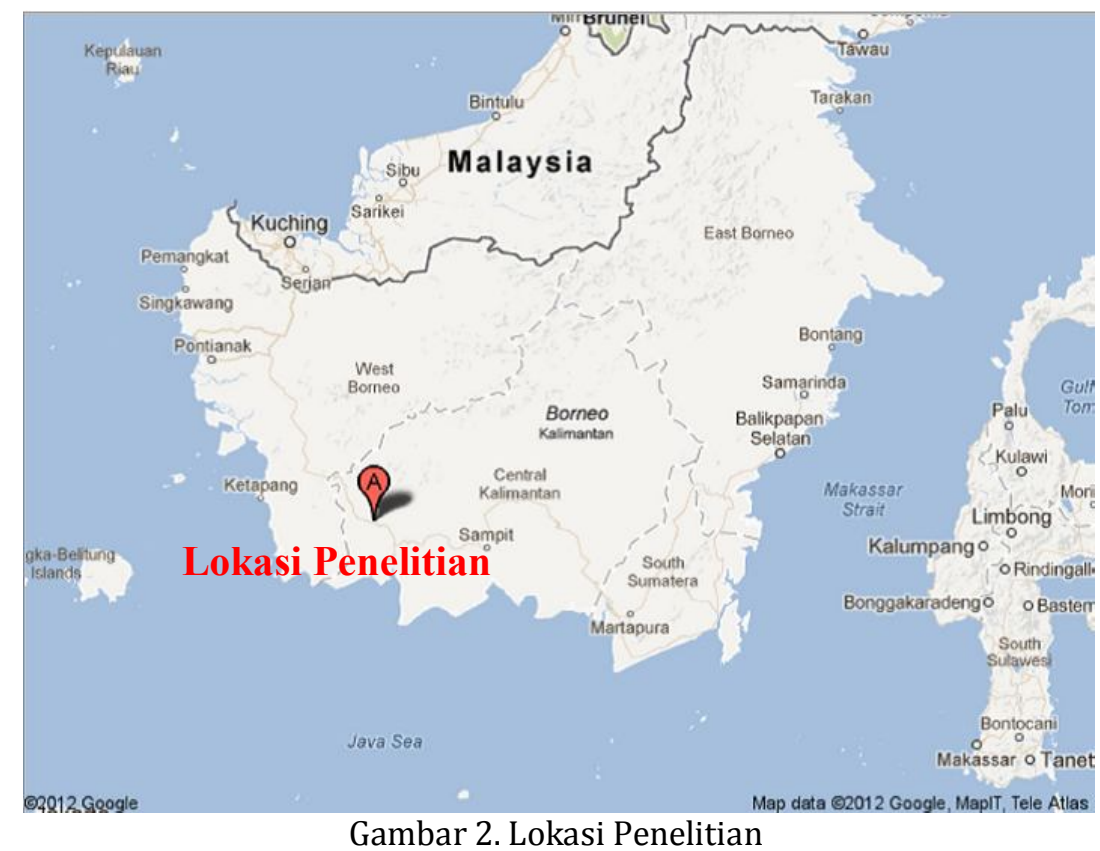

Berdasarkan Peta Geologi Regional yang diterbitkan P3G Bandung (Hermanto, dkk.,1994, Margono,dkk.,1995) Kabupaten Lamandau merupakan bagian Timur dari Paparan Sunda dan berbatasan dengan cekungan barito. Sejarah Geologi lembar Pangkalan Bun di mulai pada Trias. Pada waktu itu daerah ini mengalami pengangkatan disertai dengan kegiatan gunungapi yang menghasil Formasi Kuayan. Lokasi penelitian yang ditinjau secara geologi regional terletak di Formasi Kuayan. Formasi Kuayan (TRvk), terdiri dari breksi dengan komposisi andesit dan basal, aliran lava, batupasir tufaan dan tuf.

Di lokasi penelitian satuan batuan tidak terlihat secara jelas, lapisan penutup yang tebal dan topografi bergelombang yang landai menyulitkan dalam menemukan singkapan yang lebih segar. Batuan - batuan yang tersingkap diperbukitan memperlihatkan adanya satuan breksi-breksi dari andesit dan termineralisasikan bijih besi magnetit dan hematit dan di bagian pedataran lebih dominan ditemukan bijih-bijih limonit. Di beberapa tempat ditemukan satuan batuan andesit dan basal.

\section{Metodologi}

Penelitian ini dilakukan dengan tahapan-tahapan: studi pustaka, pemodelan sintesis, akuisisi data, pengolahan data dan interpretasi. Studi pustaka meliputi studi geologi daerah penelitian baik secara regional maupun lokal.

Pemodelan sintetik dilakukan untuk mengestimasi respon anomali magnetik di daerah penelitian dengan mengadopsi besaranbesaran yang diketahui dari studi pustaka. Respon anomali benda magnetik perlu dimodelkan karena respon anomali ini tidak hanya bergantung pada batuan bawah permukaan saja tetapi dipengaruhi oleh deklinasi dan inklinasi suatu daerah. pemodelan sintetik dilakukan dengan pendekatan objek yang berbentuk tipis dan tebal.

Proses akuisisi data menggunakan 2 magnetometer, satu berperan sebagai base yang berfungsi sebagai pengukur variasi harian medan total magnet di base station, sementara satu alat lagi berperan sebagai roover magnetometer yang berfungsi untuk mengukur total medan magnet di setiap stasiun pengukuran. Intensitas medan magnetik observasi (Hobs) diukur pada setiap stasiun yang tersebar di area penelitian.

Medan magnet IGRF adalah nilai referensi medan magnet di suatu tempat. Medan magnet IGRF merupakan nilai kuat medan magnetik ideal suatu tempat di permukaan bumi tanpa adanya pengaruh anomali magnetik batuan. 
Variasi medan magnet harian disebut koreksi harian (diurnal correction) diukur di base station. Secara umum anomali magnetik suatu tempat dapat dirumuskan sebagai (Telford,dkk., 1979) :

$$
H_{T}=H_{M}+H_{A} \pm H_{V H}
$$

dengan :

$H_{T}=$ medan magnetik total yang terukur

$H_{M}=$ medan magnetik utama bumi

$H_{A}=$ medan anomali magnetik

$H_{V H}=$ variasi harian medan magnetik bumi

\section{Hasil dan Diskusi}

Hasil pengamatan geologi di daerah penelitian menunjukan adanya singkapansingkapan batu besi berjenis hematit di beberapa titik.

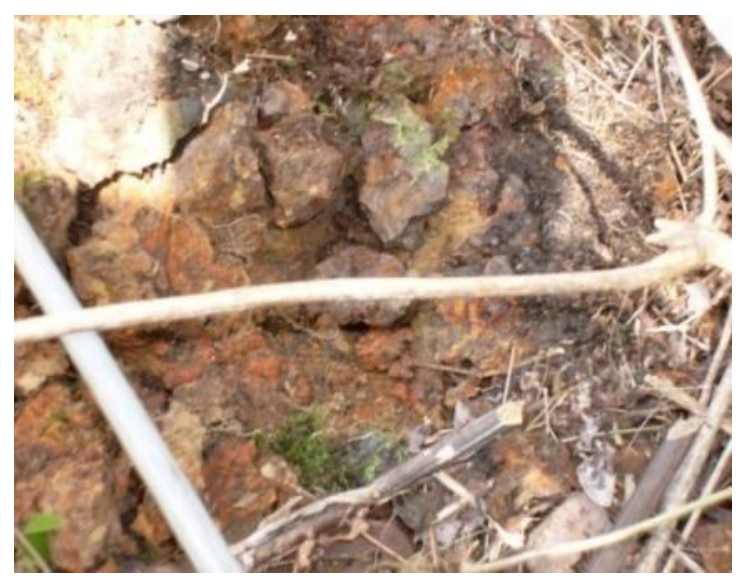

Gambar 3. Singkapan Bijih Besi Hematit-Limonit

Singkapan yang ditemukan di daerah penelitian menunjukkan sifat sebagai bijih besi dengan kemagnetan kuat (Gambar 3). Dari hasil pengamatan lapangan, ukuran dari bijih yang ada di daerah Bulik dapat dibedakan menjadi dua tipe yaitu: sebagai border yang terlepas, ditemukan di banyak tempat dengan ukuran dari sentimeter sampai beberapa meter. Singkapan ini ditemukan di lereng-lereng bukit, serta di aliran anak sungai. Pada umumnya yang berada di lereng bukit dan aliran anak sungai sebagian merupakan boulder-boulder bijih besi yang sudah mengalami pelapukan, Singkapan di punggungan bukit umumnya cukup segar yang dibatasi oleh granit fine grain dan granit.

Hasil pemetaan secara mapping daerah penelitian menghasilkan distribusi medan magnet yang telah dikoreksi ditampilkan pada Gambar 4.

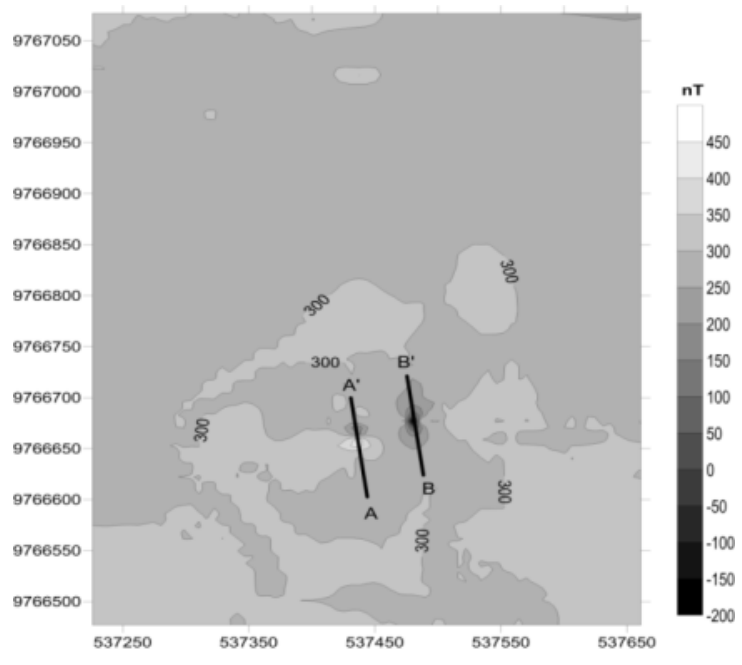

Gambar 4. Distribusi Intensitas medan magnet dalam koordinat UTM 49 M dan lintasan AA' dan $\mathrm{BB}^{\prime}$

Dari peta distribusi medan magnet maka dibuatlah 2 buah lintasan yang memotong daerah anomali untuk melihat distribusi vertikal batuan sepanjang daerah lintasan yakni lintasan $\mathrm{AA}^{\prime}$ dan lintasan $\mathrm{BB}^{\prime}$. Hasil pengolahan data dengan menggunakan perangkat lunak (freeware) mag2dc menghasilkan model distribusi suseptibilitas batuan pada lintasan $\mathrm{AA}^{\prime}$ dengan nilai korelasi 0,99 dan lintasan BB' dengan nilai korelasi 0,99 juga. Penampang distribusi suseptibilitas batuan pada lintasan AA' dapat dilihat pada Gambar 5. 


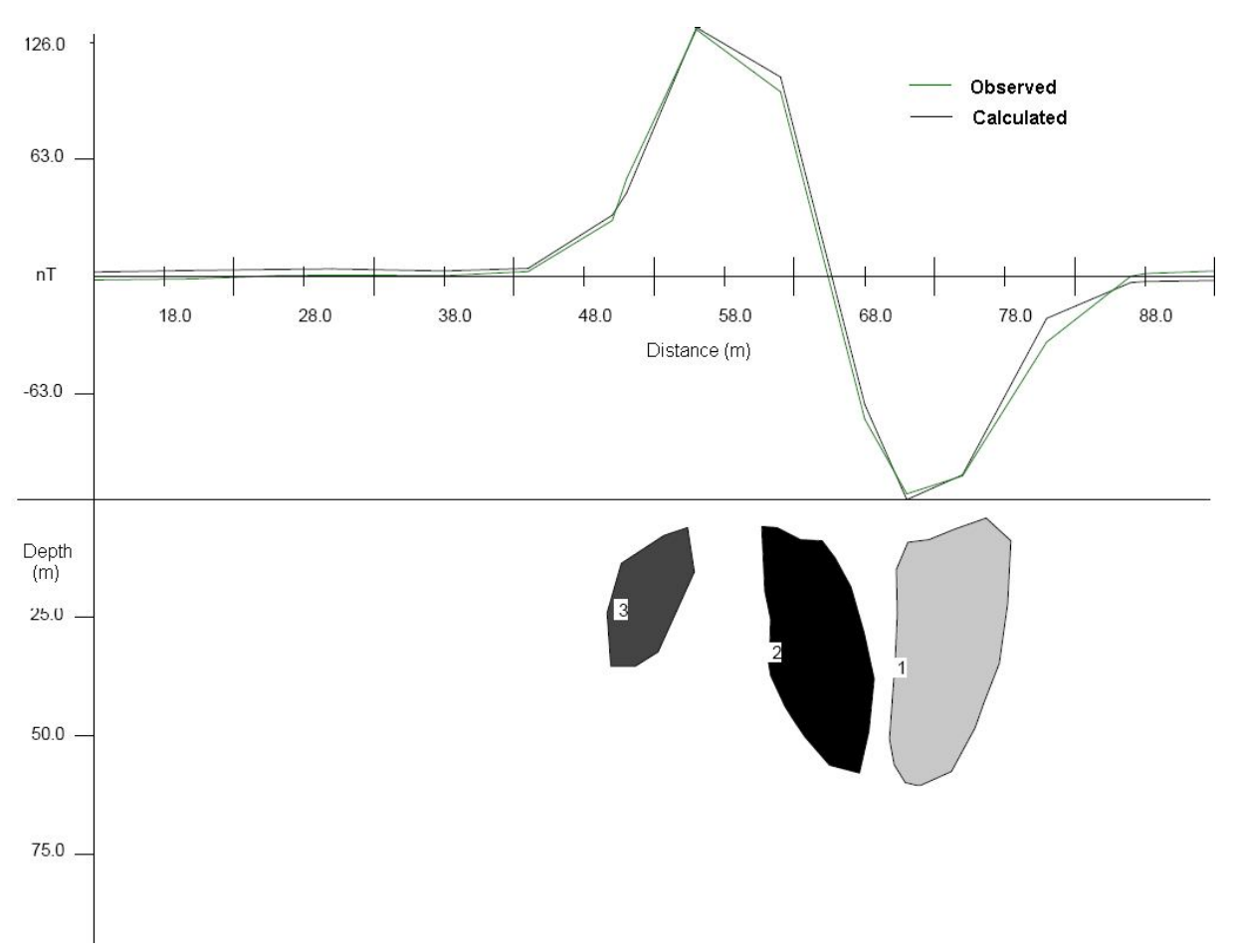

Gambar 5. distribusi suseptibilitas batuan pada lintasan AA.

Gambar 5. dapat diinterpretasikan bahwa terdapat tiga buah batu besi yang berada di sepanjang lintasan $\mathrm{AA}^{\prime}$. Batu besi pertama berbentuk border memiliki nilai suseptibilitas 0,028 SI berada pada posisi $63,4 \mathrm{~m}$ hingga $71,8 \mathrm{~m}$ dari posisi awal lintasan dan kedalaman $4 \mathrm{~m}$ hingga 60,4m dari permukaan. Berdasarkan nilai suseptibilitasnya maka dapat diduga bahwa pada batuan tersebut berjenis hematit.

Batu besi yang kedua berbentuk border memiliki nilai suseptibilitas 0,069SI berada pada posisi $54,5 \mathrm{~m}$ hingga $62,3 \mathrm{~m}$ dari posisi awal lintasan dan kedalaman 5,6m hingga 57,9m dari permukaan. Berdasarkan nilai suseptibilitasnya maka dapat diduga bahwa batuan tersebut berjenis hematit.

Batu besi ketiga berbentuk border memiliki nilai suseptibilitas 0,036 SI berada pada posisi $43,7 \mathrm{~m}$ hingga $49,8 \mathrm{~m}$ dari posisi awal lintasan dan kedalaman 5,9m hingga $35,3 \mathrm{~m}$ dari permukaan. Berdasarkan nilai suseptibilitasnya maka dapat diduga bahwa pada batuan tersebut berjenis hematit.

Sedangkan hasil pengolahan untuk lintasan BB' menghasilkan distribusi suseptibilitas sebagai berikut: 


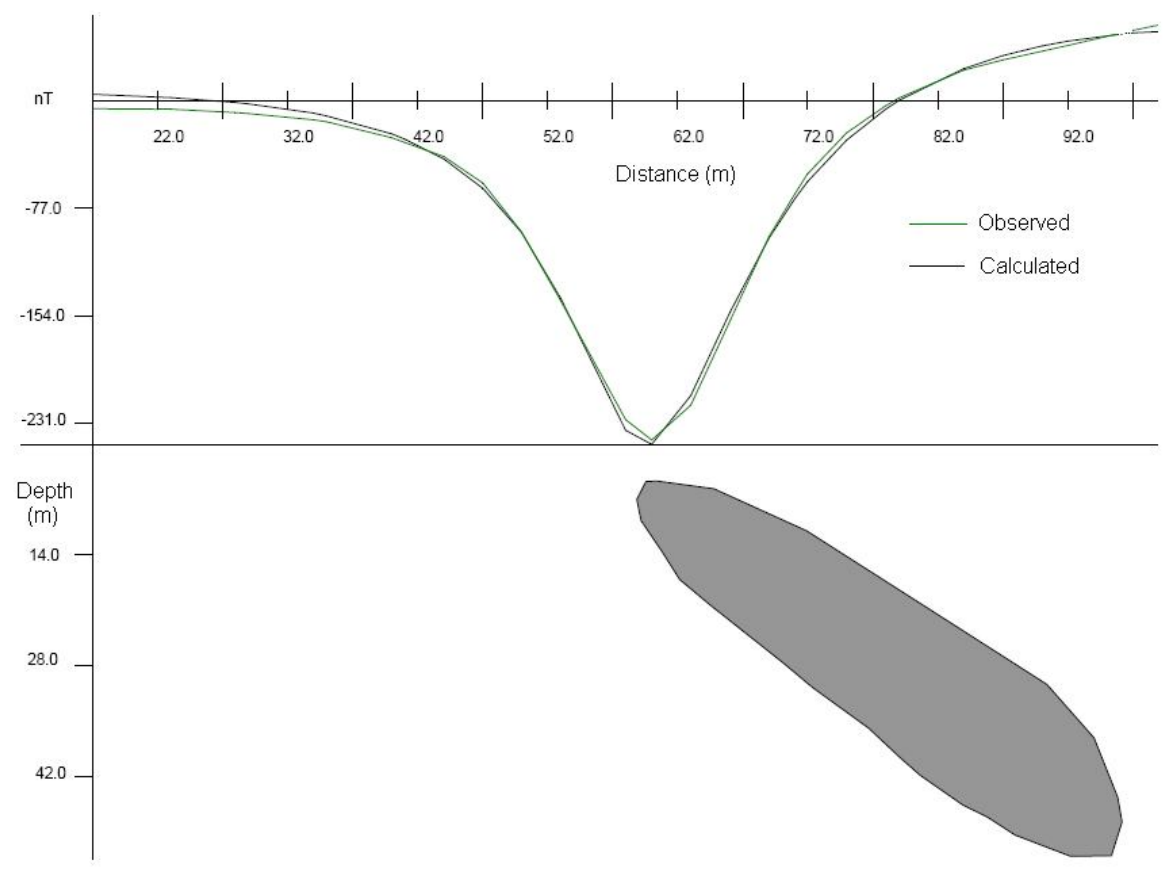

Gambar 6. distribusi suseptibilitas pada lintasan 2.

Gambar 6. dapat diinterpretasikan bahwa hanya ada satu buah batu besi yang berada di sepanjang lintasan BB'. Batu besi tersebut berbentuk border dengan nilai suseptibilitas 0,033 SI berada pada posisi 53,1m hingga $89,2 \mathrm{~m}$ dari posisi awal lintasan dan kedalaman $4,6 \mathrm{~m}$ hingga 52,2m dari permukaan. Berdasarkan nilai suseptibilitasnya maka dapat diduga bahwa pada batuan tersebut berjenis hematit yang memiliki urat magnetit.

\section{Kesimpulan}

Hasil pengamatan geologi dan pemetaan distribusi intensitas medan magnet menunjukkan keberadaan potensi bijih besi di bagian tengah wilayah penelitian. Berdasarkan distribusi nilai suseptibilitas batuan di daerah potensial tersebut diduga terdapat empat lokasi pengendapan batu besi berjenis hematit.

\section{Pustaka}

Bakrie, O., 2008, The Golden Compass (Metode Geomagnet),http://images.google.co.id/im gres?imgurl=http://grandis.files.wordpres s.com/2008/03/magnet1.gif\&imgrefurl, diakses pada tanggal 13 Agustus 2008.

Hermanto, B., Bachri, S., dan Atmawinata, S., 1994, Peta Geologi lembar Pangkalan Bun Skala 1:250.000

Margono, U. , Soejitno, T. , Santoso, T., 1995; Peta Geologi lembar Tumbang Manjul skala 1: 250.000
Ramakrishna, T.S., 2012, Gravity and Magnetic Methods in Geological Studies: Principles, Integrated Exploration and Plate Tectonics, Journal of the Geological Society of India, 80(4) , pp 584-585

Savray, R.A., Makarov, A.V., Pyshmintsev, I.Yu., Uimin, M.A.,2006, Use of a magnetic method for estimating the deformation stability of retained austenite in sheet high-strength economically alloyed steels used in the automotive industry, Russian Journal of Nondestructive Testing, 42(3), pp. 72-78,

Sharma, P.V., Magnetic method applied to mineral exploration, Ore Geology Reviews, 2(4), pp. 323-357

Telford, W.N., Geldard, L.P., Sherrif, R.E., and Keys, D.A., 1979, Applied Geophysics, Cambridge University Press, Cambridge, London,Newyork, Melbourne. 